\title{
HUMOR, BURLA E IRONÍA EN LA LITERATURA COSTARRICENSE
}

\author{
Estébana Matarrita Matarrita
}

\begin{abstract}
RESUMEN
Dos tesis sobre el humor costarricense, elaboradas de modo independiente, se entrecruzan en el incontenible dialogismo académico para dar paso, mediante la complementariedad que las reúne, a una interpretación y a una caracterización de la cultura costarricense a partir de los comportamientos discursivos que de ella se evidencian, tanto en la literatura como en la vida cotidiana.
\end{abstract}

\begin{abstract}
Two thesis about Costa Rican humor, independently wrought, interweave in the irrepresible academic dialogism to give way, by means of the complementarity that binds them, to an interpretation and a characterization of Costa Rican culture as of the discourse behaviors that evolve from it, as much in literature as in daily life.
\end{abstract}

Para ${ }^{1}$,s propósitos de este artículo he examinado una variedad de estudios sobre el humor en Costa Rica los cuales, en su mayoría, establecen siempre la presencia no del humor en general, sino de un tipo específico de humor, ese que podríamos llamar "humor crítico" y que no es otra cosa que el modo irónico.

Del examen de tales estudios he tomado particularmente dos por la profundidad de su desarrollo y por la vastedad de sus alcances; además, porque de manera curiosa son dos estudios que, habiendo sido realizados de manera simultánea pero autónoma, dialogan entre sí gracias a una serie de interrelaciones orgánicas de las que me he valido para extraer algunas conclusiones generales y de las cuales voy a presentar un breve panorama.

De forma que el único mérito de este artículo consiste, a mi modo de ver las cosas, en entrelazar dos tesis fundamentales acerca de la literatura costarricense, buscarles nuevas apoyaturas y extrapolarlas rápida y atrevidamente a una dimensión continental.

Como ya dije, esos dos planteamientos fueron concebidos casi de manera simultánea, pero de modo independiente. Uno de ellos es el de Alicia Miranda Hevia, presentado en su tesis doctoral en la Sorbona y derivado de su estudio sobre la novela Diario de una multitud de Carmen Naranjo. Esta investigación fue posteriormente publicada en forma de libro 
(Miranda 1985). El otro planteamiento es el de María Amoretti Hurtado, trabajado por casi una década, y del que rindió un pequeño avance justamente en el IV Simposio Internacional de Literatura, efectuado en 1987 en Bariloche, Argentina, y cuyo tema organizador es el de "Literatura e identidad Latinoamericana". La tesis de Amoretti nace del estudio de los relatos de uno de los clásicos de la literatura costarricense, Manuel González Zeledón, mejor conocido como Magón. Los resultados de esta investigación se publican en dos etapas, la primera parte ha dado lugar a un libro con el título de Debajo del canto, en 1987; la segunda parte se recoge en otro libro titulado Otra vez Magón, el cual está en vías de publicación, aunque tenemos entendido que en Káñina se han de publicar tres avances. Por gentileza de María Amoretti he tenido acceso a los manuscritos de ese libro.

La tesis de Miranda plantea la existencia de una corriente irónica a lo largo de toda la historia literaria de Costa Rica, cuya base o modelo fue Mariano José de Larra. Para Miranda, Larra es una especie de "signo textual" que se reescribe e inscribe continuadamente en la ironía literaria de Costa Rica hasta nuestros días.

En el segundo caso, la tesis de Amoretti afirma que el modo irónico no es sólo un rasgo típico de nuestra tradición literaria, sino una modalidad específica de discurso, característica del comportamiento lingüístico cotidiano de los costarricenses.

Sin entrar en una discusión que, aunque legítima, desbordaría los límites de este artículo, voy a manejar el término irónico de una manera muy amplia. Lo asumiré simplemente como una manifestación particular del humor que se expresa de diversas formas, entre ellas: el modo satírico y el modo paródico.

Según Miranda, desde los trabajos de Guzmán Arciniegas o Emilo Carrilla en la década de los cincuenta, se ha considerado la existencia de una corriente irónica en la literatura latinoamericana, tendencia que se marca desde sus albores, sobre todo bajo la influencia de Mariano José de Larra. Costa Rica, obviamente, no es la excepción. Los autores de la infancia literaria costarricense están de igual modo marcados por los cuadros de costumbres de Larra y emplean esta antigua modalidad discursiva para afirmar las nacientes nacionalidades y la constituyen en un medio de crítica y enfoque de la realidad del país.

Sin embargo, el recurso irónico de los cuadros de costumbres constituyó algo más que un discurso. La ironía de esos textos dio lugar a una especie de plataforma en la que se ensamblaron los discursos predominantes de la época, sobre todo los textos políticos liberales y su moral correlativa.

Así, Manuel González Zeledón, maestro del realismo costumbrista en Costa Rica, propone bajo sus textos nacionalistas una ética liberal implícita que subvierte la moral emblemática de la nacionalidad costarricense. Para Amoretti (1987), el ideologema que para ese entonces había subsumido la "esencia" del sujeto nacional era el del campesino, iconizado en la imagen del "labriego sencillo", imagen que fue oficializada en 1903 cuando Billo Zeledón, autor de la letra del Himno Nacional de Costa Rica, la introduce en ese texto-monumento en representación del sujeto costarricense. Explica Amoretti que esa imagen asentada en un texto cultural de orden patriarcal debe insertarse en el imaginario colectivo en la forma de sujeto nacional, justamente en un momento en que la sociedad costarricense está haciendo su tránsito hacia una formación social de corte liberal. El impacto de este conflicto ideológico se evidencia en la práctica literaria de finales del siglo XIX y principios de siglo XX, por el dominio del género costumbrista, el cual -como ya se afirmó- vehiculiza los 
textos políticos liberales; particularmente en los textos de Magón, según lo afirma Amoretti, este conflicto es manifiesto, pues en ellos, gracias al recurso irónico, se ridiculiza y se cuestiona el sujeto cultural representado en el "labriego sencillo".

Ya en el siglo XX, la literatura costarricense se enfila por el realismo social pero -según Miranda- el discurso irónico continúa como instrumento crítico-reformador aún en las formas más elaboradas de realismo, como es el caso de la literatura urbana. La ironía permanece en todas estas estéticas manifestándose de variadas formas: sátira, carnaval, parodia y esperpento, desde la narrativa de Carmen Lyra, pasando por Max Jiménez Huete y Carmen Naranjo, hasta las más recientes producciones. En todas estas estéticas nunca falta la crítica a la sociedad aunque varíe el tipo de referencia; en unos casos es inmediata y particularizante; en otros más oblicua o elíptica, pero siempre está ahí.

En la actualidad podríamos citar dos casos que continúan, entre otros, la tradición irónica en las letras nacionales. Se trata del escritor V.A. Mora de cuya obra y su sentido irónico también se ha ocupado María Amoretti, sobre todo en el libro titulado Introducción al suciotexto. (A propósito de Cachaza) y más recientemente en un artículo suyo titulado "Ese odioso de Mora. Un ensayo sobre el humor perverso" (Amoretti 1996). En los textos de Mora, según explica Amoretti, se abordan los temas tabúes de la sociedad costarricense gracias al discurso irónico. La crítica de Mora se orienta, no obstante, hacia un blanco diferente: los sistemas alienantes en la formación de la subjetividad cuyas tecnologías del yo niegan la libertad necesaria para un desarrollo auténtico de la persona humana. Pero el enfoque, en apariencia general, vuelve a girar en torno a una referencialidad específica: Costa Rica y su tipo humano.

El otro caso al que queremos referirnos es el del joven escritor Fernando Contreras Castro, quien llamó la atención del público lector costarricense desde su primera novela publicada en 1994: Única mirando al mar. En ella, el planteamiento se adscribe a los discursos posmodernistas con especial énfasis en el problema ecológico, pero traspolándolo al plano eminentemente social. El discurso y la gramática que el pensamiento ecológico generan se usan como interpretantes de una cierta realidad social.

Única mirando al mar describe la vida cotidiana de un grupo social marginado, el de los "buzos", así denominados porque "bucean" en las profundidades de un mar de basura, con el fin de encontrar lo necesario para subsistir: lo reciclable. Dentro de su total pobreza e ignominia, se manifiesta una solidaridad tal que evidencia cuánta sapiencia se puede derivar de las condiciones adversas, ya que ellos son capaces de sentirse dichosos en medio de su miseria material.

El tema de los desechos es el motor generador de la novela en la que se da una fuerte crítica a la sociedad de consumo y una denuncia desgarrante de la situación de los seres marginados, que forman también parte de la basura que la misma sociedad produce. Satírica y paródica, Única mirando al mar sorprende al desconectar la lógica del reciclaje de su sistema de representaciones originario y desplazarlo hacia el valor de humanidad. Cito:

Señora, me puede usted llamar Momboñombo Moñagallo, y si le interesa saber qué diablos estaba haciendo yo ahí tirado el jueves pasado, también se lo voy a decir. Señora, yo estaba ahí tirado entre la basura porque el jueves pasado, a eso de las siete de la mañana, a la hora en que pasa el camión recolector, tomé la determinación de botarme a la basura...

(....) 
Única Oconitrillo lo miraba largamente con un gesto bobalicón, sosteniéndose la mitad de la cara en la palma de la mano y al rato un "adió" se le salió solo de la boca. Única comenzó a hablar sola:

-¡Eso es lo que yo siempre he dicho, siempre, vea, por ejemplo, este hombre está bueno bueno, ¡ $a$ ah!, pero no, el desperdicio es tal que se tira a la basura cuando todavía se le puede sacar el jugo un buen rato más!... (Contreras 1994: 17-18)

La ironía reside básicamente en encontrar en el mundo del basurero la humanidad que nuestra sociedad ha tirado como desperdicio. En ese mar de basura la persona humana, despojada de la vacuidad de la sociedad moderna, se logra reciclar al enfrentar a los otros y a su propio yo desnudo. Compruébese esto en la cita siguiente:

- ¡Volver!... ¿Y para qué diablos voy yo a volver?, como si necesitara algo de allá, como si no fuera suficiente con lo que he encontrado aquí, mujer e hijo, techo, amigos y cariño de sobra. De todos modos, aunque volviera, ya nada allá arriba tendría sentido... (Contreras 1994: 89)

Al igual que en otras, en esta novela de Contreras se trasciende el localismo, pero sin renunciar a éste. En el texto son claras las referencias a la comunidad costarricense, a su transformación en sociedad de consumo y a la aguda polémica que se ha desatado con respecto a la ubicación del relleno sanitario, la cual se ha convertido incluso en tema crucial de las últimas campañas políticas.

Como se puede colegir, hasta la fecha, en la literatura costarricense el discurso irónico se mantiene como una constante caracterizada por la función crítico-moralizante, tal y como lo afirma Miranda Hevia en su obra.

El costumbrismo del siglo XIX y principios del XX, establece una tradición temática (el campesino y el medio rural) y una modalidad discursiva como mecanismo crítico (la ironía). Pero si bien su tradición temática se va metamorfoseando al ritmo del desarrollo social de su contexto, la modalidad discursiva irónica se mantiene hasta constituirse en una especie de tradición lingüística fundante de un cierto tipo de estética nacional que, como lo veremos luego, podría ligarse a una caracterización determinada del sujeto cultural y su tipo nacional.

A través del tiempo, se observa una evolución de las letras costarricenses que se adscribe al desarrollo general de la práctica literaria contemporánea bajo sucesivas etapas: el cuadro y la novela de costumbres, la novela realista, el relato del realismo social, el neorrealismo, la novela urbana y la nueva novela que plantea ya un cierto marco de preocupaciones posmodernistas. Pero indiferente a esta evolución, la ironía se mantiene como el tono y el mecanismo discursivo de preferencia para ejercer una función que le es inherente por antonomasia: su función crítica. La literatura costarricense, a pesar de los cambios de códigos estéticos y de la modernidad técnica que ha alcanzado, y de haber logrado trascender el localismo propio de los primeros realismos, mantiene siempre su tradición irónica y moralista, su función didáctica.

En el resto de Hispanoamérica, el humor y sus diversas formas parece haber evolucionado de manera diferente. En la actual novela hispanoamericana ciertamente que el humor y la ironía mantienen su función crítica y moralizante, pero se enrumba también hacia otras teleologías. 
Así, a propósito de la novela de Mario Vargas Llosa, titulada Historia de Mayta, Cornejo Polar dice que ha inaugurado:

\begin{abstract}
Dentro de la literatura peruana, la novela del entretenimiento, con lo que se modifica una tradición prácticamente unánime, a la que también pertenecen las primeras obras de Vargas Llosa, que concebía y practicaba la escritura novelesca como ejercicio de rebelación y crítica de la realidad social (En Angvick 1990).
\end{abstract}

Adrede quiero descontextualizar esta crítica de la coyuntura especial que tiene. Es decir, del cambio que se opera en la producción literaria de Vargas Llosa a partir de la publicación de Pantaleón y las visitadoras en 1973 y que lo coloca en posición de crisis frente a la crítica limeña, la cual relaciona este cambio con una evolución política del autor. Omitiendo pues este contexto, lo que nos interesa destacar en la cita de Cornejo Polar son las palabras de fundación que éste emplea para revelar la existencia de una ruptura con una cierta tradición estética en el Perú y el nacimiento de un nuevo género al que él denomina "novela del entretenimiento". La ruptura prácticamente denunciada por Cornejo Polar, a quien parece no gustarle para nada el "post" de Vargas Llosa, se refiere al abandono de la "seriedad" de sus primeros textos en favor del humor que caracteriza sus últimas novelas; lamenta que Vargas Llosa renuncie en sus nuevos textos al ejercicio del "realismo crítico" que ha caracterizado la literatura peruana hasta entonces.

En un incisivo artículo de Birger Angvik, aparecido en la revista del Centro de estudios e investigaciones Sociocríticas de la Universidad de Montpellier, éste señala la ceguera de esos comentarios, explicando que el humor de esas novelas de Vargas Llosa no ha abandonado, sin embargo, su función crítica, que lo que ha abandonado es el blanco tradicional al que normalmente se dirigía el humor crítico hispanoamericano: el orden social establecido, para dirigirse más bien a las normas y convenciones de la literatura misma, manifiestas en el propio yo-escribiente.

De igual forma podríamos citar el caso de Alfredo Bryce Echenique, para seguir siempre en la literatura peruana, la cual se ha caracterizado también -a pesar de lo que la crítica peruana ha afirmado al condenar el humor de Vargas Llosa- por una tradición humorística que algunos ligan a rasgos propios del limeño (Porras 1995).

En el caso de Bryce Echenique el humor también enfoca al yo-escribiente y hace mofa de las izquierdas y de sus preferencias estético-literarias (la falacia realista, la falacia del intencionalismo autorial, pero sobre todo se burla de los géneros cultivados por la literatura de combate: el realismo, la novela testimonial, la novela comprometida, etc). Pero Bryce Echenique hace también algo más y es lo que nos interesa destacar sobremanera.

En una investigación realizada por Rita Porras León en la Universidad de Costa Rica, esta autora afirma que en Bryce Echenique se dan dos vertientes del humor, una tradicional y otra nueva. Esas dos vertientes son:

1. El humor desenmascarador, que además de su carácter lúdico ejerce una actividad crítica.

2. El humor liberador, que permite distanciarse de los efectos negativos de la existencia, sin hacer perder conciencia de esta negatividad. 
A este último tipo de humor, Porras lo llama humor esperanzador, humor afirmativo, pues constituye ya no sólo una especie de terapia, sino sobre todo una particular actitud ante la vida caracterizada por una positividad que sigue consciente de la realidad y no la evade. Habría entonces que ver esta nueva forma de humor como una respuesta del sujeto psicológico contemporáneo ante las técnicas de subjetivación de la sociedad moderna.

Volviendo al caso de Costa Rica, la expresión humorística no ha llegado a cambiar de blanco como en Vargas Llosa, ni a constituir la positividad que Porras le adjudica en las obras de Bryce Echenique; la ironía en Costa Rica, a pesar de sus variantes y evoluciones continúa haciendo estricta crítica social (no combate entre estéticas) y mantiene todavía toda la agresividad del modo satírico. A este respecto, me gustaría hacer un breve paréntesis teórico respecto de las formas irónicas, que contribuiría a esclarecer las dificultades de esta polémica entre la positividad o la negatividad humorística de la ironía, entre lo que algunos llaman humor del entretenimiento y humor del ejercicio crítico.

Para Linda Hutcheon (1981), la parodia y la sátira son dos formas del tropo irónico que se distinguen porque la primera confronta y critica la forma estética y la segunda ataca a la sociedad. O sea, que su diferencia reside en el blanco seleccionado para la ridiculización. La sátira es una forma literaria que tiene como meta corregir ciertos vicios e ineptitudes del comportamiento humano, los cuales se consideran normalmente como extratextuales ya que casi siempre son categorías morales o sociales y no literarias. Por el contrario, la parodia, al ser etimológicamente hablando un contra-canto, sólo tiene por blanco un texto o convenciones literarias, con las cuales, no obstante, puede también manifestar un cierto acuerdo; por ello mismo, la parodia despierta más bien un sentimiento neutro y lúdico.

Estos afinamientos teóricos de Hutcheon confirman que dentro del continuum humorístico, los grados de agresividad son variables y pondrían, efectivamente, los textos humorísticos de Vargas Llosa y Echenique dentro de un movimiento subversivo que se aleja de toda política que no sea la política de un cambio de las formas, de una renovación de los géneros.

En Costa Rica, no obstante, sigue predominando el ethos satírico sobre el paródico, la crítica social sobre la crítica de las tradiciones genéricas o estéticas, aunque se pueden observar intereses paródicos en autores como Jiménez Huete o V.A. Mora, por ejemplo.

Otras son, pues, las marcas distintivas del humor y la ironía en Costa Rica y apoyamos en este aspecto, tanto las tesis de Miranda Hevia en el sentido de la permanencia de la función didáctico-satírica de la ironía del costumbrismo en las letras nacionales, a pesar de la evolución técnica que los relatos contemporáneos costarricenses evidencian; como la tesis de Amoretti Hurtado, para quien la ironía, tanto en la literatura como en las prácticas discursivas cotidianas del costarricense, es la expresión de un mecanismo compensatorio en un proceso de identificación conflictivo con el sujeto cultural de la comunidad, pues erigir al "labriego sencillo" como símbolo patrio, como retrato del sujeto cultural, no es otra cosa que "hacer de la necesidad virtud". Identificarse con esa imagen, ley es de la cultura, pero el discurso irónico le proporciona al costarricense el medio para ser y actuar de otro modo sin hacer blasfemia explícita del sujeto oficial de su cultura, guardián de la imagen que le ha sido dada de sí mismo y gracias a la cual se integra a una idea de comunidad que necesita el efecto de su continuidad histórica. 


\section{Bibliografía}

Amoretti Hurtado, María. 1995. "El odioso de Mora. Un ensayo sobre el humor perverso". Revista de Filología y Lingüística de la Universidad de Costa Rica. XXI (2): 7-16.

1987. Debajo del canto. San José: Editorial de la Universidad de Costa Rica.

1989. Introducción al sociotexto. (A propósito de Cachaza). San José: Editorial de la Universidad de Costa Rica.

Inédito. Otra vez Magón.

Angvick, Birger. 1990-2. "La risa que se vuelve mueca, el doble filo del humor y de la risa. Historia de Mayta frente a la crítica en Lima". Imprévue. Montpellier: 63-98.

Barquero Arias, Rosa María. 1996. La focalización en los relatos cortos en Los otros cuentos de Carmen Lyra. Tesis de licenciatura presentada en la Universidad de Costa Rica.

Borsò, Vittoria. "Literatura y discurso o la mirada desde afuera. Impulsos de una "hispanoamericanística" internacional para la reorganización del saber en las ciencias humanas". En: Klengel, S. (ed.). Manuscrito del artículo proporcionado por Borsò a la autora de esta publicación.

Contreras Castro, Fernando. 1994. Única mirando al mar. San José: Editorial Farben-Norma.

Cros, Edmond. 1995. D' un sujet à l'autre. Sociocritique et psychanalyse. Montpellier: ISM.

Ducrot, Oswa'd. 1972. Dire et ne pas dire. Paris: Hermann. $2^{\mathrm{a}}$ ed.

Hutcheon, Linda. 1981. "Ironie, satire, parodie. Une approche pragmatique de l'ironie". Poétique. 46, Abril.

Jiménez Huete, Max. El domador de pulgas. La Habana: Editorial Hermes. S.F.

Jolles, Andrés. 1972. Las formas simples. Chile: Editorial Universitaria.

Klengel, S. (ed.). Historia de los discursos latinoamericanos. Libro próximo a aparecer en Alemania.

Miranda Hevia, Alicia. 1985. Novela, discurso y sociedad (Diario de una multitud). San José: Mesén Editores.

Naranjo, Carmen. 1984. Los perros no ladraron. San José: Editorial Costa Rica. 
Porras León, Rita. 1995. El sentido del humor en La vida exagerada de Martín Romaña del escritor peruano Alfredo Bryce Echenique. Tesis de maestría presentada en la Universidad de Costa Rica. 